\title{
Interrelationships Among Several Person-Related Attributes in Reading and Metacomprehension: Complexity and Educational Implications
}

\author{
Lin-Miao L. Agler, PhD \\ School of Psychology, University of Southern Mississippi-Gulf Coast \\ iD https://orcid.org/o000-0002-1276-2892 \\ Larisa K. Alfsen, $\mathrm{PhD}$ \\ School of Psychology, University of Southern Mississippi-Gulf Coast \\ Contact: lin.agler@usm.edu
}

\begin{abstract}
Reading is one of the most basic academic skills. An accurate monitor of one's text comprehension (i.e., metacomprehension) is essential for effective reading as it guides learning and choices of appropriate strategy used to maximize overall understanding. The processes of reading comprehension and metacomprehension are affected by text-related, task-related, and reader- / person-related factors. One of the two purposes of this report is to provide a brief review of consistent research findings on the interrelationships among several person-related variables and the complexity of those associations in reading and metacomprehension. The person variables discussed include personality, motivation, goal orientations, self-regulation, reading strategy use, and academic effort expenditure. A second purpose is to highlight practical educational implications from the prominent research evidence for classroom teaching.
\end{abstract}

Keywords: personality; motivation; goal orientations; effort expenditure; reading; metacomprehension

Date Submitted: August 8, 2020 | Date Published: May 12, 2021

\section{Recommended Citation}

Agler, L.-M. L., \& Alfsen, L. K. (2021). Interrelationships among several person-related attributes in reading and metacomprehension: Complexity and educational implications. Journal of Educational Research and Practice, 11, 126-138. https://doi.org/10.5590/JERAP.2020.11.1.09

\section{Introduction}

A few decades ago, Baker and Brown (1984) pioneered the study of metacognition and defined this multidimensional concept in terms of two distinct components: (1) knowledge about cognition and (2) regulation of cognition. In reading, a person's knowledge about cognition, for example, is when the reader understands that a story following a sequential time progression is easier to comprehend than a story jumping back and forth between the present and the past. On the other hand, regulation of cognition in reading is one's evaluation of comprehension and regulation of comprehension (Baker, 1989). An example of evaluation of comprehension is when readers become aware of their comprehension difficulties. An example of regulation

Note: We have no known conflict of interest to disclose. Correspondence concerning this article should be addressed to Lin-Miao L. Agler, School of Psychology, University of Southern Mississippi-Gulf Coast, Long Beach, MS 39560. E-mail: lin.agler@usm.edu. Larisa K. Alfsen is now in Gautier, Mississippi. 
of comprehension, however, is when readers decide to use a rereading strategy to resolve comprehension failures by going back to previous portions of the text where comprehension was difficult.

Effective reading comprehension is essential for successful learning in school and academic achievement. One aspect of comprehension is monitoring one's own comprehension, a mechanism by which learners evaluate their own understanding and decide to employ effective study strategies when comprehension is not achieved (Thiede et al., 2003). The ability to accurately evaluate one's own comprehension is called metacomprehension accuracy (Maki et al., 1994; Wiley et al., 2005). Research evidence has shown that individuals are generally poor at evaluating how well they have understood a text after reading (Commander et al., 2014; Dunlosky \& Lipko, 2007; Lin et al., 2001; Zabrucky et al., 2009). Although individuals differ in their self-evaluation ability, they usually tend to be overconfident (Lin-Agler et al., 2004; Schaefer et al., 2004). In attempts to determine factors that distinguish individuals with good and poor monitoring accuracy, researchers have examined many variables related to texts, tasks, and individual differences (see Lin \& Zabrucky, 1998; Stolp \& Zabrucky, 2009, for reviews). Personality is an aspect of individual differences found to contribute to reading and metacomprehension accuracy. One of our purposes is to provide a brief overview of consistent research findings on personality variables in relation to motivation, goal orientations, selfregulation, and effort expenditure in reading and metacomprehension. Because of the complexity of the relationships among those variables, another goal is to discuss evidence-based applicable value for classroom teaching practice.

\section{Personality}

Personality refers to a person's characteristic way of behaving, thinking, and feeling (Costa \& McCrae, 1992; McCrae \& Costa, 1997) and can be conceptualized in terms of a cluster of dimensions. According to the widely accepted Five-Factor Model or "Big Five" personality model (John \& Srivastava, 1999; McCrae \& Costa, 1997), five major dimensions are used to capture individuals' habitual ways of thinking, feeling, and behaving: (1) neuroticism, (2) extraversion, (3) openness to experience or intellect, (4) agreeableness, and (5) conscientiousness. Neurotic people tend to exaggerate their emotional ups and downs, get upset easily, and are moody and emotionally unstable. Extraverted people are often friendly, assertive, communicative, and have high energy. Openness to experience is characteristic of individuals with high intellect, imagination, creativity, and an independent, challenge-seeking mind set. Kind, warm, sympathetic, trustful, considerate, and cooperative individuals are described as being agreeable. Those high in conscientiousness are viewed as responsible, organized, hard working, goal directed, and dependable (John \& Srivastava, 1999).

\section{The Role of Personality, Self-Regulation, and Motivation in Reading and Metacomprehension}

The ability to self-regulate learning is often a distinctive feature of academically superior students. The concept of self-regulation involves goal-setting, ensuring that learning goals are met by monitoring one's learning, and employing strategies when learning obstacles are encountered (Bidjerano \& Dai, 2007). Research has shown that self-regulated learning influences academic success and that some personality traits have direct links to students' tendency to self-regulate during learning (e.g., Bidjerano \& Dai, 2007; Zabrucky et al., 2015). For example, the traits of conscientiousness and openness to new experiences heighten the selfregulatory tendency (Bidjerano \& Dai, 2007; Swanberg \& Martinsen, 2010). Students with those traits are better at regulating their time and effort and are more inclined to use additional learning strategies, such as elaboration and critical thinking. Self-regulated learning and motivation are intertwined concepts; to selfregulate learning, learners must develop an ability to monitor the ongoing learning process and, thus, be able to modify, adjust, and maximize their learning. This self-regulation mechanism requires a conscious and effortful control process that, in turn, requires motivation. Motivation is what drives people to behave the way 
Agler \& Alfsen., 2021

they do and can be influenced by individual characteristics such as one's goals, needs, and beliefs in selfcompetence (Guthrie et al., 1999).

Research evidence has shown that motivation is a trait closely related to the Big Five factor, conscientiousness, which is found to be the most important and consistent predictor for academic performance when it is measured by students' grade point average (GPA) (e.g., Kaufman et al., 2008; Richardson \& Abraham, 2009). Bidjerano and Dai (2007) speculated that the effect of conscientiousness on GPA is mediated by motivation. Other researchers argued that conscientiousness is a multifaceted constant and that motivation is one of the subtraits that constitute conscientiousness, paralleling with persistence, diligence, and industriousness, which are three other subtraits (e.g., Hough \& Ones, 2001; Richardson \& Abraham, 2009; Roberts et al., 2005). The relationship between motivation and conscientiousness was further elaborated by Roberts and Wood (2006), who suggested that motivation is a narrower, state-like trait that can be more easily influenced by situational factors compared with conscientiousness, which is a relatively stable and global personality factor. According to the neo-socioanalytic theory of personality proposed by Roberts and his colleagues (Roberts \& Wood, 2006; Bogg et al., 2008), conscientiousness, like the other Big Five traits, is located at the highest level of the personality hierarchy with motivation at the midlevel of the hierarchy and individuals' discrete thoughts, emotions, and behaviors at the lowest level. Based on this hierarchy, motivation as a midlevel construct is more closely related to global personality factors than the lowest level environmentally mediated thoughts or behaviors and, thus, may have a greater impact on conscientiousness. Richardson and Abraham (2009) studied the long-range predictive effect of conscientiousness on university students' GPA over a 9-month period and the mediating power of achievement motivation on the effect of conscientiousness. The results of their study offered support to the neo-socioanalytic theory of personality, indicating that conscientiousness was the most important predictor of GPA among the Big Five factors and, even more importantly, such predictive power was fully mediated by students' achievement motivation.

In addition to students' overall GPA, previous researchers have also examined the role of motivation on individual subject matters. Research findings show that motivation contributes to text comprehension in several ways. For example, Guthrie et al. (1999) measured reading motivation in terms of curiosity, challenge, involvement, recognition, competition, and reading efficiency. The researchers found that motivation positively correlated with the amount of reading in students in $3 \mathrm{rd}, 5^{\text {th }}, 8$ th, and 9th grades. In turn, reading amount positively correlated with reading comprehension after controlling for other variables known to relate to reading comprehension, such as past achievement, reading self-efficacy, and prior knowledge. In addition, the contribution of reading motivation to text comprehension was more prominent in the older students (8th and gth graders) than the younger students.

\section{Educational Implications for Classroom Practice}

\section{Foster Conscientiousness}

Teachers can establish firm deadlines for task completion and enforce reasonable consequences for failing to adhere to deadlines to help foster students' conscientiousness. As noted previously, research evidence has consistently shown that conscientiousness, compared to the other personality traits, is the most reliable predictor for academic success across subject domains measured by GPA. A global and relatively stable multifaceted trait, conscientiousness innately encompasses situational state-like traits such as motivation, persistence, industriousness, and diligence. Having a strong sense of responsibility and dependability is what motivates students to work hard persistently and to continue trying without giving up. Conscientious students tend to set their goals at mastering a task and learn the task in a meaningful way. In the classroom, conscientious students are (1) better at regulating their study time and effort, (2) more inclined to use learning 
Agler \& Alfsen., 2021

strategies to enhance learning quality, (3) motivated to read more often, and (4) better in reading comprehension. To encourage students' sense of dependability and duty, teachers should require assignments that reinforce students' careful and thorough work, set high but realistic criteria on required assignments, and make sure that students are given a reasonable timeline to complete each task. The evaluative criteria used in the classroom should be adjusted according to student ability; it is essential, however, that each student be held accountable to the timeline and standards set up for them by the teacher. For a complex project or task that involves multiple steps or phases to complete, instead of setting up a final completion deadline, teachers should implement a step-by-step sequence of deadlines to maximize student success for each phase leading to the final completion of the whole project. Enforcing quality completion of academic work based on a timetable helps foster students' conscientiousness and, in turn, helps students build a motivating force that drives academic success, leading to later career and occupational success.

\section{The Role of Goal Orientations in Reading and Metacomprehension}

Two broad motivational goals, or purposes, are relevant to learning and academic outcomes: performance and mastery orientations (Guthrie et al., 1999; Ferla et al., 2010; Ikeda et al., 2016). A performance goal orientation refers to the tendency to demonstrate one's capability to outperform others. A mastery goal orientation refers to the tendency to improve one's capabilities. When reading is examined, students' motivational orientation has been found to relate to their reading comprehension monitoring accuracy and their ability to detect errors within texts (Kroll \& Ford, 1992). Such ability is referred to as "metacomprehension," an individual's ability to accurately assess one's own comprehension. Metacomprehension involves knowledge about cognition and regulation of cognition (Dunlosky \& Lipko, 2007; Wiley et al., 2005). Regulation of cognition during reading consists of evaluation and regulation or control of comprehension, which is a component of self-regulated learning. In the study by Kroll and Ford (1992), two forms of motivational orientation in learning were measured. One was ego-involved motivational orientation, which referred to goals to demonstrate ability to oneself and others without exerting much effort for mastery. The other was task-involved motivational orientation, referring to goals to master the task regardless of one's abilities or required effort compared to others. Researchers found that ego-oriented students performed more poorly at error detection while reading and were less accurate at comprehension monitoring compared to task-oriented students.

Similar findings were observed in Zhou's (2013) investigation of achievement goal profiles adopted by students with different levels of metacomprehension accuracy. In Zhou's study, four types of goals-masteryapproach, performance-approach, mastery-avoidance, and performance-avoidance-were assessed using the 12-item Achievement Goal Questionnaire adopted from Elliot and McGregor (2001). Individuals with mastery-approach or performance-approach goals are viewed as desiring to achieve higher levels of task mastery or performance scores, respectively, and tend to be more involved in self-evaluation. On the other hand, individuals with mastery-avoidance and performance-avoidance goals are less concerned with their levels of task mastery or task performance and, thus, less focused on self-evaluation. Results of the study showed that students with performance-approach goals, similar to ego-involved individuals who focus on selfability demonstration (Kroll \& Ford, 1992), tended to be overconfident in predicting their comprehension performance compared to students with other goal orientations. This overconfidence phenomenon associated with the performance-goal orientation is repeatedly supported by more recent research evidence (e.g., Ferla et al., 2010; Ikeda et al., 2016), and such overconfidence can lead to a lack of persistence in trying, resulting in poorer learning results (Ferla et al., 2010). Current studies have further demonstrated that mastery-goaldriven students often outperform those who adopt other goal orientations in learning (e.g., Hong et al., 2020) and that avoidance goal orientations, especially performance-avoidance goals, are often related to maladaptive academic self-handicapping (Shih, 2005). According to Shih (2005), academic self-handicapping refers to the use of strategies that help provide external excuses for potential failure instead of being perceived as lack of ability when poor performance occurs. This concept is rooted in the theory of self-worth and one's 
Agler \& Alfsen., 2021

desire to maintain a positive self-image. Examples include going out with friends and procrastinating in studying the night before a test.

Lin et al. (2001) examined the effects of ego-involved motivational orientation on metacomprehension accuracy; such ego-involved motivational orientation is related to the concept of self-worth and self-image. Students' self-image presentation was determined by the extent to which they focused on positive and impressive self-presentation in social situations. The researchers distinguished between two types of individuals. One type, labeled as self-monitors, described individuals who tend to create a positive self-image by using situational cues as feedback to regulate their public self-image. They usually can accurately monitor their comprehension and estimate performance using environmental cues and feedback. Another type tends to focus on promoting desirable self-presentation and denying self-inadequacies, like the performanceavoidance students in Shih's study (2005). These individuals are often inept at using social cues and feedback to improve their self-image, and they showed low ability to accurately monitor their own comprehension. Additionally, in the study by Lin-Agler et al. (2004), self-monitors were also found to exert more effort in test preparation. Using performance feedback on the first test, self-monitors increased their study time for subsequent tests during the academic semester. In this study, researchers also examined the effects of another personality-related characteristic, competitiveness, on metacognitive self-assessment. The results indicated that competitive students, resembling the performance-goal-oriented individuals previously mentioned, had higher self-evaluations of text comprehension and higher confidence in test performance compared with less competitive students.

As noted previously, individuals' motivational orientations (i.e., goals) can affect both metacomprehension accuracy and choice of learning strategies. Goals that individuals may choose to pursue can be influenced by their personality. For example, McCabe et al. (2013) investigated the relations between context-specific (e.g., school and work) achievement goals and the Big Five personality traits. The researchers examined the same four achievement goals studied by Zhou (2013): mastery-approach (or task-mastery), performance-approach, mastery-avoidance, and performance-avoidance (avoidance of incompetence) goals. Mastery-approach goals focus on the self-mastery of the tasks. Performance-approach goals focus on better performance in relation to others. Mastery-avoidance and performance-avoidance goals focus on avoiding incompetence in relation to oneself or others, respectively. The researchers found that mastery-approach goals were strongly and positively related to conscientiousness and agreeableness traits whereas performance-approach goals were negatively related with agreeableness. In addition, mastery-avoidance, performance-avoidance, and performance-approach goals were found to positively relate to neuroticism. Similarly, Vaughn et al. (2008) found a positive correlation between openness to experience and motivation to pursue promotion-oriented goals but a negative correlation between openness to experience and motivation to pursue prevention goals. A high degree of openness to experience is often reflected in characteristics such as a preference for novelty, creativity, intensity, and nonconventional pursuits. On the other hand, a low level of openness to experience is associated with a preference for routine, security, conventionality, and simplicity. According to the researchers, the characteristics shown in those with high openness motivate individuals to adopt promotionoriented goals that focus on obtaining possible gains by pursuing one's hopes and aspirations, whereas the characteristics demonstrated by those individuals low in openness motivate them to adopt prevention-driven goals that target avoiding possible losses by fulfilling one's duties and obligations.

\section{Encourage Mastery Goals and Nurturing Creativity}

Students who adopt mastery (task-involved) goals are more persistent in expending effort to achieve learning success, better at self-regulating learning, and more accurate in self-evaluations of performance. In contrast, performance-driven goals relate to inflated student confidence (i.e., overconfidence) without increased actual performance, whereas performance-avoidance goals associate with students' maladaptive self-handicapping behaviors. The modern education system in the U.S. is driven by uniform testing and score-based 
Agler \& Alfsen., 2021

performance; assessing levels of mastery using diverse measurements is often overlooked. Instead of encouraging the pursuit of mastery goals or promotion-driven goals, the testing approach used in the school system is likely to strengthen students' tendency to adopt avoidance goals or prevention-driven goals (that is, to avoid making mistakes or performance failure to preserve a positive self-image). Classroom teachers can encourage students to set goals to master learning and promote their knowledge base by designing tasks that emphasize creativity and critical thinking over true/false or choice answers. The former involves deeper thought processing whereas the latter is often based on more superficial memorization. Teachers can mix graded tasks with proficiency tasks; the latter allow students to "pass" with a single try or multiple tries by demonstrating their learning proficiency without the fear of receiving a poor letter grade. Such proficiency tasks can include a mixture of oral and written questions so that students can be trained in both writing and speaking skills.

\section{How Do Motivation and Goal Orientations Affect Comprehension Strategy Use?}

Metacomprehension accuracy is an important aspect of text comprehension. However, being able to accurately assess one's comprehension is not enough for successful comprehension outcomes. Successful comprehension also requires selection of effective strategies to resolve misunderstanding or lack of understanding. As noted, individuals' motivational orientations can affect their metacomprehension accuracy. Research findings show that individuals' motivational orientation can also influence their choices of study strategies. For example, Miele et al. (2009) investigated the role of basic motivations in strategy selection and the subsequent effects on reading comprehension outcomes in college students. The researchers distinguished between individuals' basic needs for protection and security and their needs for attainment and growth. The former are prevention-focused individuals who vigilantly guard against making mistakes, and the latter are promotion-focused individuals who eagerly aim at promoting comprehension and learning. According to Miele and colleagues (2009), people may be motivated to achieve their goals using different strategies, such as vigilant strategies versus eager strategies. Prevention-motivated individuals tend to sustain comprehension by minimizing incomprehension, using strategies that include vigilant monitoring of potential misunderstanding and careful evaluation of text information for inconsistencies. On the other hand, promotion-motivated individuals desire to maintain best performance and focus on maximizing comprehension using strategies that allow them to advance their learning, including making risky assessments of information or eagerly searching for new information. Results of Miele et al.'s (2009; experiment 1) study showed that readers' motivation orientations influenced their choice of reading strategies; in particular, prevention-focused readers were more likely to use a rereading strategy to understand a difficult text compared with promotion-focused individuals. The results, however, did not show a difference in the reading comprehension test performance between the two motivation orientations.

In their follow-up experiment, Miele et al. (2009; experiment 2) further measured readers' metacognitive strategy use in relation to their motivational orientations by inserting confusing sentences into the text that explained the rules and strategies of a novel card game. To further test the participants' efforts to clarify any misunderstandings, the researchers manipulated the level of confusion in the text by including sentences that were clearly contradictory to each other (contradictory condition) or by presenting ambiguous sentences that were not directly contradictory (ambiguous condition). The results showed that both prevention-focused and promotion-focused individuals used rereading strategy in the contradictory text condition. However, prevention-focused individuals were more likely to adopt a rereading strategy than promotion-focused individuals in the ambiguous text condition. In addition, prevention-focused participants performed better than promotion-focused participants on a multiple-choice comprehension test in the ambiguous condition. In conclusion, prevention-focused individuals who are motivated to avoid mistakes or misunderstanding are inclined to reread and reprocess information when encountering difficult texts or texts with directly contradictory or mildly confusing information whereas promotion-driven individuals who are motivated to 
Agler \& Alfsen., 2021

achieve maximum comprehension are more likely to read on and move along for new information during reading, except when overt contradictions occur in texts.

Subsequently, the participants' comprehension of the text about the novel card game was further tested in one round of the game on a computer. Prevention-focused individuals performed better than promotion-focused individuals on this transfer task in the ambiguous text condition. The results suggested that preventionfocused individuals' motivational orientation influenced their choice of effective strategy use, resulting in better comprehension as well as better ability to transfer their comprehension to actual card games.

Rereading allowed prevention-focused individuals to clarify confusion before moving along; in comparison, promotion-focused individuals chose to continue their reading, hoping for clarification in the future. As Miele et al. (2009) pointed out, effective strategy use (such as the rereading strategy adopted by prevention-focused individuals) is especially important when encountering information without prior knowledge or when information is confusing or contradictory. Conversely, the researchers also suggested that prevention-oriented individuals tend to indiscriminately reread, and such across-the-board rereading strategy is not always beneficial because they did not perform any better in comprehension tests than promotion-driven individuals when texts did not present contradictory or confusing information. This indiscriminate reread-and-review habit is often time consuming. Thus, when the opportunity to reread is deprived under time constraints, such as when a timed test is administered, a common classroom practice, prevention-motivated students' reading performance may be compromised more than that of promotion-motivated students.

\section{Balance Between Motivational Orientations and Strategy Use}

As stated, promotion-focused students have a higher tendency to seek to master knowledge and achieve maximum learning compared with prevention-focused students; however, when it comes to reading strategy use, prevention-focused students are actually more likely than the promotion-focused students to employ a simple reading strategy, which is rereading (Miele at al., 2009). Prevention-focused motivation is rooted in the avoidance behavior, most likely driven by fear of failure, worries, and anxiety. Students who are prevention-focused channel their energy to avoid making mistakes instead of focusing on advancing their learning without reservation. Such worries drive them to use a basic strategy (rereading) to avoid failure in reading comprehension; however, this strategy seems to be adopted indiscriminately regardless of the text condition (Miele et al., 2009). On the other hand, promotion-driven students are more likely to continue through the reading process without stopping to reread because they are less worried about failure to understand. Even though rereading, in general, can be an effective strategy to assist further comprehension, it may be unnecessary under certain circumstances, including when a text is fairly easy to understand; when there is no contradictory or ambiguous information in the text to create possible misunderstanding or lack of understanding; or when readers have an extensive vocabulary both in breadth and in depth, indicating they are good in comprehension (Binder et al., 2017). Unnecessary rereading may result in time loss for tasks with limited completion time. Teachers can play a critical role in helping students strike a balance between keeping their fear of failure in check and employing reading strategies wisely when such strategies are needed to benefit reading comprehension.

\section{The Role of Personality, Motivation Goals, and Competence Beliefs in Effort Expenditure}

As noted, monitoring and regulating one's own comprehension and learning require effort. Past research has linked conscientiousness to academic effort expenditure, persistence, and academic performance (e.g., Chamorro-Premuzic \& Furnham, 2003; Trautwein et al., 2006). An important variable that often correlates with all the variables mentioned previously is competence beliefs. In a series of studies, Trautwein et al. (2009) examined the relationships between conscientiousness, domain-specific competence beliefs, and academic effort among German high school students. Academic effort and competence beliefs were measured for mathematics, English as a foreign language, and French as a foreign language, using either a questionnaire or a diary measure. For example, participants were asked to rate the degree of their agreement with 
statements such as "I really work hard on classwork assignments in mathematics [English]" (p. 1118) to assess their academic effort and with statements such as "If I make an effort, I can do all of my math [English] homework [classwork]" to assess their competence beliefs (p. 1118). Persistence was measured by a 3-item questionnaire (e.g., "Even if my mathematics homework is difficult, I don't give up quickly," p. 1121). A German version of the NEO Five Factor Inventory (NEO-FFI) was used to measure conscientiousness. The results indicated that there was a moderate correlation between conscientiousness and competence beliefs, and that each of the two variables significantly and independently correlated with academic effort. Interestingly, the relations between competence beliefs and academic effort were domain specific. That is, competence beliefs in mathematics did not relate to academic effort in English and vice versa. On the other hand, the predictive power of conscientiousness on academic effort extended across all academic subjects examined in the study. In conclusion, academic effort expenditure is influenced by both the conscientiousness personality trait and domain-specific competence beliefs, both of which predict academic performance, as shown in students' grades (Trautwein et al., 2009).

Vasalampi et al. (2014) studied personality traits and effort exertion among upper secondary school students in Germany. In this study, the researchers also examined the role of autonomous (i.e., intrinsic) goal motivation in students' willingness to exert effort in academic and social life domains. Agreeableness and conscientiousness personality traits were measured using the German version of NEO-FFI. To assess academic and social goals, participants were asked to indicate their six goals for the coming months and years. Those who indicated at least one academic or friendship goal (labeled as academic and social goals) were included in the study. To assess their motivation for pursuing a goal, participants rated their goals in terms of their perceived reasons for action. The motivational reasons to achieve a goal ranged from extrinsic, or the most controlled ("I am pursuing this goal because somebody else wants me to or because the situation demands it," p. 101), to intrinsic, or the most autonomous (the reason to pursue a goal is "because of the enjoyment it gives me," p. 101). The relative autonomous motivation scores were then calculated for each personal goal for each participant. Participants also rated their willingness to invest effort for each of the goals. Both personality traits (conscientiousness and agreeableness) and autonomous (intrinsic) motivation were found to significantly and positively relate to the willingness to exert academic and social effort, but these relationships are domain specific. Conscientious students were very willing to exert effort to achieve their academic goals (18.8\% of variance accounted for) but were not inclined to exert effort in the social life domain. Agreeable students, on the other hand, had the tendency to exert effort in both academic and social domains, although significantly more effort was distributed in the social life domain (10.7\% of variance accounted for compared to 2.2\% for the academic domain). Students who had autonomous (intrinsic) motivation in academic goals showed high willingness to exert effort in both academic life and social life domains, except the willingness to exert effort in the academic life domain was much higher than it was in the social life domain (20.2\% of variance accounted for in the former compared to $9.2 \%$ of variance accounted for in the latter).

\section{Promote Intrinsic Motivation and Conscientious/Responsible Behaviors}

Research evidence has consistently shown that conscientiousness and intrinsic motivation are two robust factors related to an increased level of academic effort exertion, effort expenditure quality, task persistence, and academic performance across domains (e.g., Sheldon \& Elliot, 1998; Trautwein et al., 2006; Trautwein et al., 2009; Turban et al., 2007; Vasalampi et al., 2014). Teachers can increase accountability in the classroom to elevate a sense of responsibility and conscientiousness in students. Setting realistically high academic standards and ensuring the standards are met by all students using individually based student-teacher contracts that take individual ability differences into consideration will promote self-responsibility. For instance, implementing individually based student-teacher contracts can help students internalize a sense of achievement when they fulfill their contract and, consequently, promote their intrinsic motivation to achieve 
Agler \& Alfsen., 2021

in the future. Making classroom materials and activities more relatable to students will also increase their interest in learning and encourage intrinsic motivation.

\section{Encourage Students' Competence Beliefs and Confidence: Be Domain Specific, Not Global}

Students' competence beliefs and confidence levels are found to be domain specific (e.g., Sheldon \& Elliot, 1998; Sheldon \& Kasser, 1995; Vasalampi et al., 2014). For example, competence beliefs in math do not translate to those in reading within the same individual, or vice versa. By the same token, confidence in social domains does not necessarily correlate to confidence in academic domains. Students' competence beliefs consistently predict the amount of effort they exert and the persistence level of their effort, but this holds true only in the domain in which they feel competent. Thus, attempts made to boost student confidence and selfbeliefs will render more successful outcomes if they target a specific student ability instead of global, allinclusive competence, such as IQ. For example, statements such as "You did well" or "You are so smart" are global and fail to address a specific domain-related ability and thus are less convincing and less likely to help students internalize a sense of confidence. Better comments might be something like "It is very clever that you paused to think about the operational steps for this 2-digit multiplication problem first, and then you thought it aloud and talked it out before you wrote down the solution on paper." An important point to keep in mind is that confidence does not generalize across domains unless students have an opportunity to improve on the domain of their weakness. Therefore, when teachers design activities and tasks targeting a particular academic domain (e.g., math or reading) or an individual subject/topic under a domain (e.g., algebra or geometry), they can help students build up competence self-beliefs in the specific domain or subject over time when they allow students to succeed in it repeatedly. Additionally, a socially self-confident student (for example, an extravert) is not necessarily academically self-confident.

\section{Conclusion}

We have presented some consistent research findings on the role of personality variables, self-regulation, motivation, goal settings, effort expenditure, and strategy use in reading and metacomprehension. Overall, research has shown a complex pattern of associations among these variables in reading and metacomprehension. Consistent findings suggest that these variables can jointly or interactively impact a students' self-regulatory behavior, motivational orientations, effort persistence, feelings or self-beliefs, and approaches to cognitive strategy use. Educational implications derived from the empirical evidence for practical teaching applications were highlighted and discussed in depth for educators' use in the classroom setting. 
Agler \& Alfsen., 2021

\section{References}

Baker, L. (1989). Metacognition, comprehension monitoring, and the adult reader. Educational Psychology Review, 1(1), 3-38. https://doi.org/10.1007/BF01326548

Baker, L., \& Brown, A. L. (1984). Metacognitive skills and reading. In P. D. Pearson, R. Barr, M. L. Kamil, \& P. Mathensal (Eds.), Handbook of Reading Research (pp. 353-394). Longman.

Bidjerano, T., \& Dai, D. (2007). The relationship between the Big-Five model of personality and self-regulated learning strategies. Learning \& Individual Differences, 17(1), 69-81.

https://doi.org/10.1016/j.lindif.2007.02.001

Binder, K. S., Cote, N. G., Lee, C., Bassette, E., \& Vu, H. (2017). Beyond breadth: The contributions of vocabulary depth to reading comprehension among skilled readers. Journal of Research in Reading, 4O(3), 333-343. https:/doi.org/10.1111/1467-9817.1206920

Bogg, T., Voss, M. W., Wood, D., \& Roberts, B. W. (2008). A hierarchical investigation of personality and behavior: Examining neo-socioanalytic models of health-related outcomes. Journal of Research in Personality, 42, 183-207. https://doi.org/10.1016/j.jrp.2007.05.003

Chamorro-Premuzic, T., \& Furnham, A. (2003). Personality predicts academic performance: Evidence from two longitudinal university samples. Journal of Research in Personality, 37(4), 319-338. https://doi.org/10.1016/Soo92-6566(02)00578-o

Commander, N. E., Zhao, Y., Li, H., Zabrucky, K. M., \& Agler, L.-M. L. (2014). American and Chinese students' calibration of comprehension and performance. Current Psychology, 33(4), 655-671. https://doi.org/10.1007/s12144-014-9235-4.

Costa, P. T., \& McCrae, R. R. (1992). The NEO PI/NEO-FFI manual. Psychological Assessment Resources. https://doi.org/10.1037/1040-3590.4.1.5

Dunlosky, J., \& Lipko, A. R. (2007). Metacomprehension: A brief history and how to improve its accuracy. Current Directions in Psychological Science, 16(4), 228-232. https://doi.org/10.1111/j.14678721.2007.00509.x

Elliot, A. J., \& McGregor, H. A. (2001). A 2 x 2 achievement goal framework. Journal of Personality and Social Psychology, 8o(3), 501-519. https://doi.org/10.1037/0022-3514.80.3.501

Ferla, J., Valcke, M., \& Schuyten, G. (2010). Judgments of self-perceived academic competence and their differential impact on students' achievement motivation, learning approach, and academic performance. European Journal of Psychology of Education, 25, 519-536. https://doi.org/10.1007/s10212-010-0030-9

Guthrie, J. T., Wigfield, A., Metsala, J. L., \& Cox, K. E. (1999). Motivational and cognitive predictors of text comprehension and reading amount. Scientific Studies of Reading, 3(3), 231-256.

https://doi.org/10.1207/s1532799xssro303_3

Hong, W., Bernacki, M. L., \& Perera, H. N. (2020). A latent profile analysis of undergraduates' achievement motivations and metacognitive behaviors, and their relations to achievement in science. Journal of Educational Psychology, 112(7), 1409-1430. http://dx.doi.org/10.1037/eduoooo445

Hough, L. M., \& Ones, D. S. (2001). The structure, measurement, validity, and use of personality variables in industrial, work, and organizational psychology. In N. Anderson, D. S. Ones, H. K. Sinangil, \& C. 
Agler \& Alfsen., 2021

Viswesvaran (Eds.), Handbook of industrial, work and organizational psychology (Vol. 1, pp. 233277). Sage.

Ikeda, K., Yue, C. L., Murayama, K., \& Castel, A. D. (2016). Achievement goals affect metacognitive judgments. Motivation and Science, 2(4), 199-219. http://dx.doi.org/10.1037/motooooo47

John, O. P., \& Srivastava, S. (1999). The Big Five trait taxonomy: History, measurement, and theoretical perspectives. In L. A. Pervin \& O. P. John (Eds.). Handbook of personality: Theory and research (2nd ed.), pp. 102-138. Guilford.

Kaufman, J. C., Agars, M. D., \& Lopez-Wagner, M. C. (2008). The role of personality and motivation in predicting early college academic success in non-traditional students at a Hispanic-serving institution. Learning and Individual Differences, 18, 492-496. https://doi.org/10.1016/j.lindif.2007.11.004

Kroll, M. D., \& Ford, M. L. (1992). The illusion of knowing, error detection, and motivational orientations. Contemporary Educational Psychology, 17, 371-378. https://doi.org/10.1016/0361-476X(92)90075-A

Lin, L.-M., Moore, D., \& Zabrucky, K. M. (2001). An assessment of student's calibration of comprehension and calibration of performance using multiple measures. Reading Psychology, 22, 111-128. https://doi.org/10.1080/02702710119125

Lin, L.-M., \& Zabrucky, K. M. (1998). Calibration of comprehension: Research and implications for education and instruction. Contemporary Educational Psychology, 23, 345-391. https://doi.org/10.1006/ceps.1998.0972

Lin-Agler, L. M., Moore, D, \& Zabrucky, K. M. (2004). Effects of personality on metacognitive selfassessments. College Student Journal, 38(3), 453-461.

Maki, R. H., Jonas, D., \& Kallod, M. (1994). The relationship between comprehension and metacomprehension ability. Psychonomic Bulletin \& Review, 1(1), 126-129. https://doi.org/10.3758/BFo3200769

McCabe, K. O., Van Yperen, N. W., Elliot, A. J., \& Verbraak, M. J. P. M. (2013). Big Five personality profiles of context-specific achievement goals. Journal of Research in Personality, 47, 677-707. https://doi.org/10.1016/j.jrp.2013.06.003

McCrae, R. R., \& Costa, P. T., Jr. (1997). Personality trait structure as a human universal. American Psychologist, 52, 509-516. http://dx.doi.org/10.1037/0003-066X.52.5.509

Miele, D. B., Molden, D. C., \& Gardner, W. L. (2009). Motivated comprehension regulation: Vigilant versus eager metacognitive control. Memory and Cognition, 37(6), 779-795. https://doi.org/10.3758/MC.37.6.779

Richardson, M., \& Abraham, C. (2009). Conscientiousness and achievement motivation predict performance. European Journal of Personality, 23, 589-605. https://doi.org/10.1002/per.732

Roberts, B. W., Chernyshenko, O. S., Stark, S., \& Goldberg, L. R. (2005). The structure of conscientiousness: An empirical investigation based on seven major personality questionnaires. Personnel Psychology, 58, 103-139. https://doi.org/10.1111/j.1744-6570.2005.00301.x 
Roberts, B. W., \& Wood, D. (2006). Personality development in the context of the neo-socioanalytic model of personality. In D. K. Mroczek, \& T. D. Little (Eds.). Handbook of personality development (pp. 1139). Lawrence Erlbaum Associates Publishers.

Schaefer, P. S., Williams, C. C., Goodie, A. S., \& Campbell, W. K. (2004). Overconfidence and the Big Five. Journal of Research in Personality, 38(5), 473-480. https://doi.org/10.1016/j.jrp.2003.09.010

Sheldon, K. M., \& Elliot, A. J. (1998). Not all personal goals are personal: Comparing autonomous and controlled reasons for goals as predictors of effort and attainment. Personality and Social Psychology Bulletin, 24, 546-557. https://doi.org/10.1177/0146167298245010

Sheldon, K. M., \& Kasser, T. (1995). Coherence and congruence: Two aspects of personality integration. Journal of Personality and Social Psychology, 68, 531-543. http://dx.doi.org/10.1037//oo223514.68.3.531

Shih, S.-S. (2005). Taiwanese sixth graders' achievement goals and their motivation, strategy use, and grades: An examination of the multiple goal perspective. The Elementary School Journal, 106(1), 39-58. https://doi.org/10.1086/496906

Stolp, S., \& Zabrucky, K. M. (2009). Contributions of metacognitive and self-regulated learning theories to investigations of calibration of comprehension. International Electronic Journal of Elementary Education, 2(1), 7-31. https://iejee.com/index.php/IEJEE/article/view/255

Swanberg, A. B., \& Martinsen, Ø. L. (2010). Personality, approaches to learning and achievement. Educational Psychology 3o(1), 75-88. https://doi.org/10.1080/01443410903410474

Thiede, K. W., Anderson, M. C. M., \& Therriault, D. (2003). Accuracy of metacognitive monitoring affects learning of texts. Journal of Educational Psychology, 95, 66-73. https://doi.org/10.1037/o0220663.95.1.66

Trautwein, U., Lüdtke, O., Kastens, C., \& Köller, O. (2006). Effort on homework in grades 5-9: Development, motivational antecedents, and the association with effort on classwork. Child Development, 77, 10941111. http://doi.org/10.1111/j.1467-8624.2006.00921.x

Trautwein, U., Lüdtke, O., Roberts, B. W., Schnyder, I., \& Niggli, A. (2009). Different forces, same consequence: Conscientiousness and competence beliefs are independent predictors of academic effort and achievement. Journal of Personality and Social Psychology, 97, 1115-1128. https://doi.org/10.1037/a0017048

Turban, D. B., Tan, H. H., Brown, K. G., \& Sheldon, K. M. (2007). Antecedents and outcomes of perceived locus of causality: An application of self-determination theory. Journal of Applied Social Psychology, 37, 2376-2404. http://dx.doi.org/10.1111/j.1559-1816.2007.00263.x.

Vasalampi, K., Parker, P., Tolvanen, A., Lüdtke, O., Salmela-Aro, K., \& Trautwein, U. (2014). Integration of personality constructs: The role of traits and motivation in the willingness to exert effort in academic and social life domains. Journal of Research in Personality 48, 98-106.

https://doi.org/10.1016/j.jrp.2013.11.004

Vaughn, L. A., Baumann, J., \& Klemann, C. (2008). Openness to experience and regulatory focus: Evidence of motivation from fit. Journal of Research in Personality 42, 886-894.

https://doi.org/10.1016/j.jrp.2007.11.008 
Wiley, J., Griffin, T. D., \& Thiede, K. W. (2005). Putting the comprehension in metacomprehension. The Journal of General Psychology, 132, 408-428. https://doi.org/10.3200/GENP.132.4.408-428

Zabrucky, K. M., Agler, L.-M. L., \& Moore, D. (2009). Metacognition in Taiwan: Students' calibration of comprehension and performance. International Journal of Psychology, 44(4), 305-312. https://doi.org/10.1080/00207590802315409

Zabrucky, K. M., Moore, D., Agler, L.-M. L., \& Cummings, A. M. (2015). Students' metacomprehension knowledge: Components that predict comprehension performance. Reading Psychology, 36(7), 627642. https://doi.org/2010.1080/02702711.2014.95053620

Zhou, M. (2013). University student's goal profiles and metacomprehension accuracy. Educational Psychology, 33(1), 1-13. https://doi.org/10.1080/01443410.2012.730325 reviewed journal that provides a forum for studies and dialogue about developments and change in the field of education and learning. The journal includes research and related content that examine current relevant educational issues and processes. The aim is to provide readers with knowledge and with strategies to use that knowledge in educational or learning environments. JERAP focuses on education at all levels and in any setting, and includes peer-reviewed research reports, commentaries, book reviews, interviews of prominent individuals, and reports about educational practice. The journal is sponsored by The Richard W. Riley College of Education and Leadership at Walden University, and publication in JERAP is always free to authors and readers. 